\title{
Symptomatic Bradycardia - An Offbeat Side Effect of Clonidine in Antihypertensive Dose
}

\author{
Abhishek Subhash Chande ${ }^{1}$, Sunil Kumar², Sachin Ratanlal Agrawal ${ }^{3}$ \\ 1, 2, 3 Department of General Medicine, Datta Meghe Institute of Medical Sciences, \\ Sawangi (Meghe), Wardha, Maharashtra, India.
}

\section{PRESENTATION OF CASE}

A 40-years-old male was brought to the emergency room with a history of syncope, weakness, dizziness and fatigue. He denied any history of ischemic heart disease, chronic respiratory disease or any neurological disorder. He was a non-smoker and non-alcoholic. On taking a detailed history, it was revealed that the patient was recently diagnosed with systemic hypertension and put on tab clonidine $0.1 \mathrm{mg}$ (twice a day) by a general practitioner.

On general examination, patient was conscious as well as oriented to time, place and person, and his blood pressure on admission was 140 / $90 \mathrm{mmHg}$ and pulse rate of 42 beats / min. On systemic examination, cardiovascular system exam was suggestive of normally heard heart sounds, and there were no signs of heart failure. Respiratory system examination revealed clear chest on both sides on auscultation and air entry was equal bilaterally. Central nervous system examination was normal with findings of power of 5 / 5 in all 4 limbs, intact sensations, deep tendon reflexes were normally present and bilateral plantar was flexor in response.

On per abdomen examination, abdomen was soft and non-tender with no evidence of any dilated veins / scar marks. There was no evidence of any organomegaly, no free fluid could be demonstrated on palpation and percussion and bowel sounds were heard normally. Patient's blood investigations were done to rule out any apparent cause for bradycardia. His investigation reports were as follow: haemoglobin - $11.1 \mathrm{gm} / \mathrm{dL}$, mean corpuscular volume - $96 \mathrm{fl}$, white blood cells - 5400 / cubic mm, total platelet count - 341000 / cubic mm, serum urea - $32 \mathrm{mg}$ / dL, serum creatinine - $1.5 \mathrm{mg} / \mathrm{dL}$, serum sodium - $138 \mathrm{mEq} / \mathrm{L}$, serum potassium - $5.0 \mathrm{mEq} /$ $\mathrm{L}$, alkaline phosphatase - $72 \mathrm{U} / \mathrm{L}$, serum glutamic pyruvic transaminase - $39 \mathrm{U} / \mathrm{L}$, serum glutamic oxaloacetic transaminase - $31 \mathrm{U} / \mathrm{L}$, total protein - $7.3 \mathrm{gm} / \mathrm{dL}$, serum albumin - $3.9 \mathrm{gm} / \mathrm{dL}$, serum globulin - $3.4 \mathrm{gm} / \mathrm{dL}$, total bilirubin - $0.4 \mathrm{mg} / \mathrm{dL}$, conjugated bilirubin - $0.2 \mathrm{mg} / \mathrm{dL}$, unconjugated bilirubin - $0.2 \mathrm{mg} / \mathrm{dL}$, random blood sugar - $76 \mathrm{mg} / \mathrm{dL}$, urine routine and microscopy-normal findings with albumin-nil, sugar-nil.

His 2D echocardiography was suggestive of normal systolic and diastolic left ventricular function with mild left ventricular hypertrophy with normal left ventricle ejection fraction of $60 \%$.

As no attributable cause was found, it was decided to taper and stop clonidine as an antihypertensive drug. One day later, the patient's heart rate improved to about 80 - 100 beats / min and thereafter would continue to be the same of 82 beats / $\mathrm{min}$ and blood pressure was $140 / 90 \mathrm{mmHg}$.

He was symptomatically stable, and his blood pressure, temperature and blood sugar level were within normal limits. Furthermore, his heart rate slowly stabilized rather than showing constant variations. The patient was kept under observation for two days; later as he was symptomatically stable, was discharged with regular follow ups for the same cause. During discharge his heart rate was 82 beats / min and blood pressure was $140 / 90 \mathrm{mmHg}$.
Corresponding Author: Dr. Abhishek Subhash Chande, Room No. G-15, Yashoda Boys Hostel, AVBRH, Sawangi (Meghe), Wardha - 442001, Maharashtra, India. E-mail: achande54@gmail.com

DOI: $10.14260 /$ jemds/2021/55

How to Cite This Article:

Chande AS, Kumar S, Agrawal SR. Symptomatic bradycardia - an offbeat side effect of clonidine in antihypertensive dose. J Evolution Med Dent Sci 2021;10(04):248249, DOI: 10.14260/jemds/2021/55

Submission 13-07-2020,

Peer Review 27-10-2020,

Acceptance 03-12-2020,

Published 25-01-2021.

Copyright (C) 2021 Abhishek Subhash Chande et al. This is an open access article distributed under Creative Commons Attribution License [Attribution 4.0 International (CC BY 4.0)] 


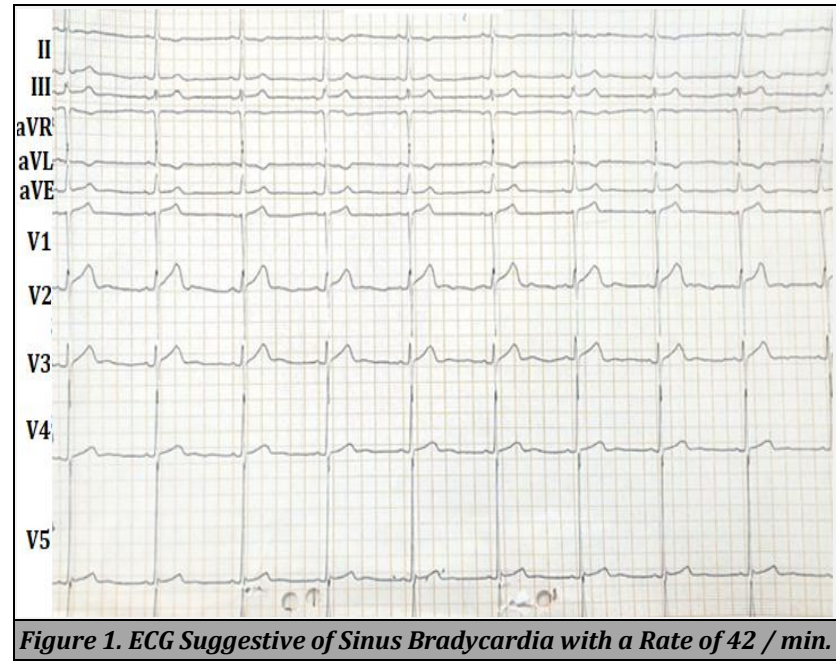

\section{DISCUSSION}

Clonidine is an imidazoline derivative drug that acts by positively stimulating alpha receptors. The usual side effect of clonidine is hypotension, especially at low dosage. Therefore, once or twice daily regimen is sufficient to stabilize the blood pressure. The clinical picture of clonidine toxicity includes any of the following features : an initial rise in the blood pressure which is later followed by hypotension, fall in heart rate, giddiness, areflexia or hyporeflexia, respiratory depression, hypothermia, generalized weakness, irritable behaviour, and pupillary miosis. ${ }^{4} \mathrm{~A}$ high level of toxicity is known to cause alteration in the electrical conduction system although this effect can be reversible and non-life threatening if treated promptly, dysrhythmias, apnea, coma, and seizures. From virtue of its mechanism of action, bradycardia was thought to be a prominent side effect of clonidine use. However, later with increase is its usage, it was discovered that bradycardia appears only in case of clonidine overdose or in case of poisoning or infusion therapy or clonidine addiction. ${ }^{5}$ Bradyarrhythmia, as a side effect, may have several manifestations and may be symptomatic or asymptomatic. In our patient, he was asymptomatic throughout his stay once oral clonidine was discontinued. In case symptomatic bradycardia develops, it presents as syncope, weakness, dizziness and fatigue with ambulation and palpitations.

Bradycardia reported so far is generally sinus bradycardia but rarely junctional bradycardia or an advanced degree of atrioventricular (AV) block has been seen found. The incidence of bradycardia may be roughly estimated to $0.3 \%$. The effect of clonidine has been found to be masked in patients who are hypertensive or normotensive even if there is severe bradycardia. ${ }^{6}$

The commonly suggested mechanisms by which clonidine can cause bradycardia are as follows: alteration of adrenergic outflow from the central pathway which is the autonomic centre located in the brain, improvement in the vagal tone in the body thereby affecting the AV node and causing increase in the delay of the cardiac impulse, reduction in the release of epinephrine, norepinephrine and dopamine at cardiac postganglionic sympathetic nerve endings, and a rate altering effect directly on the conductive system of the heart (negative dromotropy).5,6 Bradycardia, a very rarely seen side effect especially in adult age group, at therapeutic dosing has been reported before. ${ }^{3}$ Risk factors include biochemically altered or deranged kidney function tests (clinically apparent or not), history of similar episodes after consumption of sympatholytic drugs, current usage of other adjunctive sympatholytic drugs ${ }^{3}$ and underlying heart condition which can make oneself susceptible to drug induced bradycardia e.g. sick sinus syndrome, sinus dysfunction or electrical conduction system abnormalities.

\section{CONCLUSIONS}

Bradycardia as a side effect of oral clonidine at therapeutic dosing is not yet a well-established fact. However, it must be kept in mind that when a patient on oral clonidine therapy, whatever may be the indication, shows bradycardia with no obvious cause, clonidine induced bradycardia must be ruled out.

Financial or other competing interests: None.

Disclosure forms provided by the authors are available with the full text of this article at jemds.com.

\section{REFERENCES}

[1] Isbister GK, Heppell SP, Page CB, et al. Adult clonidine overdose: prolonged bradycardia and central nervous system depression, but not severe toxicity. Clin Toxicol 2017;55(3):187-92.

[2] Philbin KE, Bateman RJ, Mendelowitz D. Clonidine, an alpha2-receptor agonist, diminishes GABAergic neurotransmission to cardiac vagal neurons in the nucleus ambiguus. Brain Res 2010;1347:65-70.

[3] Sandweiss AJ, Morrison CM, Spichler A, et al. A case report of clonidine induced syncope: a review of central actions of an old cardiovascular drug. BMC Pharmacol Toxicol 2018;19(1):6.

[4] Seger DL, Loden JK. Naloxone reversal of clonidine toxicity: dose, dose, dose. Clin Toxicol (Phila) 2018;56(10):873-9.

[5] Hov KR, Neerland BE, Andersen AM, et al. The use of clonidine in elderly patients with delirium; pharmacokinetics and hemodynamic responses. BMC Pharmacol Toxicol 2018;19(1):29.

[6] Givens ML. Toxic bradycardias in the critically ill poisoned patient. Emerg Med Int 2012;2012:852051. 